\title{
Assessing the Potential Risk of Oil-Field Produced Waters Using a Battery of Bioassays/Biomarkers
}

\author{
Jian Li $\cdot$ Mei Ma $\cdot$ Qing Cui $\cdot$ Zijian Wang
}

Received: 23 July 2007 / Accepted: 12 May 2008/Published online: 31 May 2008

(C) Springer Science+Business Media, LLC 2008

\begin{abstract}
A battery of in vitro bioassays was conducted to assess the potential risks of organic extracts from oilfield produced wastewaters and from the receiving waters. In SOS/umu bioassay for the genotoxicity, our results showed that direct and indirect genotoxic substances were observed and metabolic activation greatly enhanced the genotoxic effects. In Ethoxyresorufin- $O$-deethylase bioassay, levels of AhR-agonists, expressed as 2,3,7,8-tetrachlorodibenzop-dioxin equivalences, varied from 13.3 to $16.7 \mathrm{pg} \mathrm{L}^{-1}$. We conclude that oilfield produced wastewater contains substantial quantity of indirect genotoxic substances exclusive of AhR agonists. Both genotoxic and AhR agonistic chemicals could not be effectively removed by the treatment processes.
\end{abstract}

Keywords Oilfield wastewater - AhR-agonists . Genotoxicity $\cdot$ Environmental risk

Oilfield produced water, which is released during the drilling process and associated with crude oil exploration and production, has long been known as one of the largest waterborne sources of organic pollution. It is composed of easily biodegradable light petroleum hydrocarbons as well as more recalcitrant chemicals, such as polycyclic aromatic hydrocarbons (PAHs) and BTEX (benzene, toluene, ethylbenzene, and xylenes) (Dórea et al. 2007). Researchers

J. Li · M. Ma $\cdot$ Q. Cui $\cdot$ Z. Wang $(\bowtie)$

State Key Laboratory of Environmental Aquatic Chemistry,

Research Center for Eco-Environmental Sciences,

Chinese Academy of Sciences, P.O. Box 2871,

Shuangqing Rd 18, Haidian District, Beijing 100085,

People's Republic of China

e-mail: wangzj@rcees.ac.cn have associated diverse groups of contaminants, including metals, PAHs, heterocyclic amines, and pesticides with genotoxicity of surface waters (Kira et al. 1999). In addition, PAHs in environmental samples may contribute also greatly to Ah-agonistic effects (Qiao et al. 2006). Surface waters receiving large quantities of waste water from industrial can be a serious problem to public health and aquatic ecosystems. So, it is important to evaluate and control the impact of discharge. Until now, waste water and surface water are generally assessed by chemical analysis; however, the chemical approach identifies only a few percent of contaminants and provides limited information on potential adverse effects in the environment, especially under chronic, low-level exposures. It was thus considered that bioassays can be used to indicate the presence and potential effects of contaminants and therefore, are useful in ecological risk assessment. Bioassays enable estimation of the total biological activity of all compounds that act through the same mode of action present in environmental media, and they also integrate possible interactions among contaminants (Giesy et al. 2002). It is for this reason that the whole effluent toxicity testing is being included by USEPA in assessments of effluents (US EPA 2002).

Bioassays for cytotoxic, genotoxic and Ah receptor (AhR)-agonistic effects are based on molecular and cellular responses of enzymatic or metabolic activity of cells and are usually sensitive and specific. For genotoxicity, the SOS/umu test using Salmonella typhimurium strain TA1535/pSK1002 has been developed and standarized (ISO/DIS 13829, 2000). In addition, the inhibition of bacterial growth could be used as a parameter to measure cytotoxic potential of the samples. Ethoxyresorufin- $O$ deethylase (EROD) is a member of the AhR-responsive enzymes. Ethoxyresorufin- $O$-deethylase induction in H4IIE rat hepatoma cells can be used to pinpoint the sources and 
identities of Ah-agonistic or dioxin-like chemicals (Ma et al. 2005). It is generally regarded as being an early warning signal for the presence of dioxins, furans, polychlorinted biphenyls (PCBs), PAHs and related chemicals (Safe 1990). In this paper, a battery of in vitro bioassays was conducted to assess the removal efficiencies of toxic chemicals by the aerobic-anaerobic treatment processes in the oilfield produced water treatment plant. The bioassays, which included cytotoxicity, genotoxicity and AhR-agonist effects, were also conducted with a view towards the potential ecological and health risk of the effluent discharge to the receiving river.

\section{Materials and Methods}

Produced water samples were collected in March 2005 from an oilfield in Jidong region located in northeast China. The wastewater treatment plant (WWTP) includes suspended anoxic and contact aerobic units before discharge into Qinglong river. Six $24 \mathrm{~h}$ composite samples were collected in acid-washed glass bottles pre-rinsed with sample water (Fig. 1). Salinity and temperature were measured in situ. Water samples were processed immediately upon arrival in the laboratory.

In the laboratory, each $4 \mathrm{~L}$ sample was filtered through $0.7 \mu \mathrm{m}$ glass fiber filters (APFF, MILLIPORE, USA) and extracted by solid phase extraction (Oasis HLB cartridges, $6 \mathrm{~mL}, 500 \mathrm{mg}$, Waters, USA). The columns were then

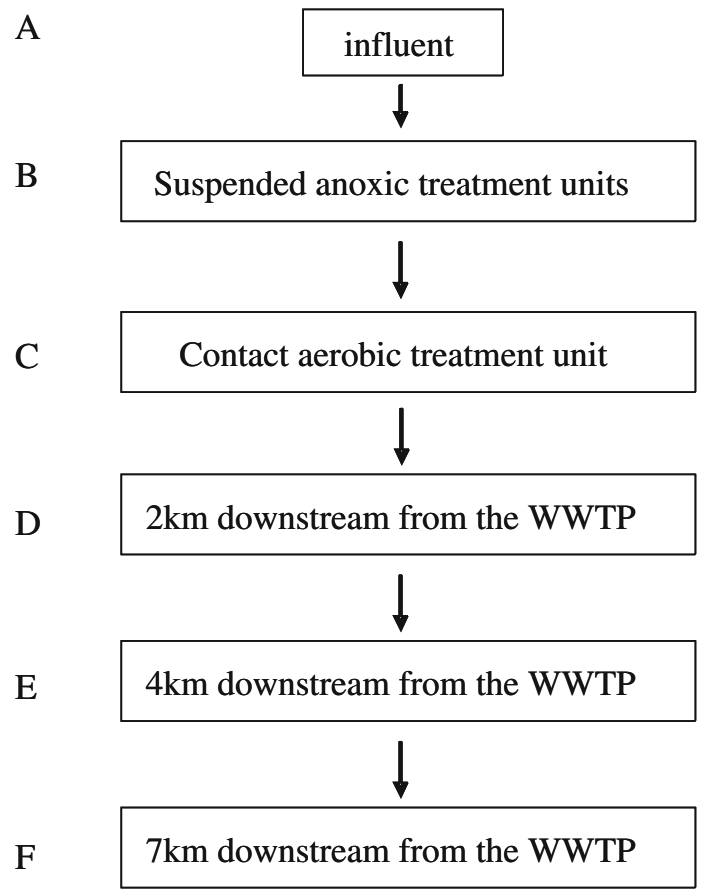

Fig. 1 Flow scheme of the biological treatment system for produced water, Jidong oilfield and sampling location eluted three times with $5 \mathrm{~mL} \mathrm{CH}_{2} \mathrm{Cl}_{2}$ and eluates were combined. The extracts were pre-concentrated to $1 \mathrm{~mL}$ by a rotary evaporator (Büchi Vac V-800, Switzerland), then evaporated to dryness with a gentle nitrogen flow. The residues were dissolved in $0.5 \mathrm{~mL}$ dimethyl sulfoxide (DMSO, Sigma, USA) and diluted by a 0.5 -fold dilution series. The DMSO solution $(5 \mu \mathrm{L})$ was added to $995 \mu \mathrm{L}$ culture medium and homogenized. The resulting solvent concentration in the culture medium did not exceed $0.5 \%$, a concentration which did not affect cell growth. Five dilution levels were tested in addition to a DMSO control.

The SOS/umu test was conducted according to the modified microplate version of Oda et al. (1985). The bacterial strain Salmonella typhimurium TA1535/pSK1002 was provided by Osaka Prefectural Institute of Public Health, Japan. The microsomal fraction (S9 mix) was prepared from livers of male Sprague-Dawley rats pretreated with 3-methylcholantherene, and was used for metabolic activation. Selective medium ( $\mathrm{pH} 7.0$ ) containing $20 \mu \mathrm{g} \mathrm{mL}^{-1}$ ampicillin and medium of bacterial culture were prepared following the procedures of Oda et al. (1985). Each microplate included two positive controls, benzo(a)pyrene (BaP, Sigma, USA) as indirect mutagen and 4-nitroquinoline- $N$-oxide (4-NQO, Sigma, USA) as direct mutagen, and a negative control (DMSO). A total of $5 \mu \mathrm{L}$ of serial dilutions of test samples were combined with $995 \mu \mathrm{L}$ of medium without or with $\mathrm{S} 9$ mix resulting in a test culture. A total of $200 \mu \mathrm{L}$ of the test cultures was transferred into each well of the 96-well plate and incubated at $37^{\circ} \mathrm{C}$ with vigorous orbital shaking (800 rpm) on a titer plate shaker (Heidolph TITRAMAX 1000 , Germany) for $2 \mathrm{~h}$, then the cell density of the culture was measured at $600 \mathrm{~nm}$ wavelength $\left(\mathrm{OD}_{600}\right.$, TECAN GENios A-5002, Austria). A total of $100 \mu \mathrm{L}$ test culture was transferred to a new 96-well plate, after addition of $100 \mu \mathrm{L}$ of Z-buffer $\left(60 \mathrm{mM} \mathrm{Na} \mathrm{HPO}_{4}, 40 \mathrm{mM} \mathrm{NaH} \mathrm{PO}_{4}, \mathrm{pH} 7.0\right.$, $10 \mathrm{mM} \mathrm{KCl}, 1 \mathrm{mM} \mathrm{MgSO}$, $50 \mathrm{mM}$ 2-mercaptoethanol), $5 \mu \mathrm{L}$ sodium dodecyl sulfate (SDS, $0.01 \%$ ) and $5 \mu \mathrm{L}$ chloroform, the assays were carefully mixed (vortex $25 \mathrm{~s}$ ) and preincubated for $10 \mathrm{~min}$ at $37^{\circ} \mathrm{C}$. The enzyme reaction was started by adding $30 \mu \mathrm{L} o$-nitro-phenylgalactopyranoside (13.3 $\mathrm{mg} \mathrm{mL}^{-1}$, dissolved in Z-buffer). The assays were incubated at $37^{\circ} \mathrm{C}$ on a titer plate shaker for $20 \mathrm{~min}$ and terminated by the addition of $50 \mu \mathrm{L} \mathrm{Na}_{2} \mathrm{CO}_{3}(1 \mathrm{M})$. After centrifugation at 12,000 g for $15 \mathrm{~min}, 200 \mu \mathrm{L}$ of the supernatant was transferred into a new 96-well plate. The optical density at 420 and $550 \mathrm{~nm}\left(\mathrm{OD}_{420}\right.$ and $\left.\mathrm{OD}_{550}\right)$ was determined. The $\beta$-galactosidase activity was calculated according to the following equations:

$\mathrm{IU}=\frac{1000\left(\mathrm{OD}_{420}-1.75 \times \mathrm{OD}_{550}\right)}{t \times v \times \mathrm{OD}_{600}}$

where IU $-\beta$-galactosidase activity; $t$ - the time of reaction $(\min ) ; v$ - the volume of culture used in the assay $(\mathrm{mL})$. 
The cytotoxic potential of water sample was expressed by the growth ratios $\left(\mathrm{GR}=\mathrm{OD}_{600}\right.$ sample $/ \mathrm{OD}_{600}$ solvent blank $)$. GR $<0.8$ which represents a $20 \%$ inhibition of biomass were considered to be indicative of cytotoxicity of water samples. To avoid interferences, the genotoxic effect was quantitatively expressed as induction ratios (IR $=I_{\text {sample }} /$ $\mathrm{IU}_{\text {solvent blank }}$ ) under a given water volume. Induction ratios above 2.0 were scored as sufficient positive results; and those below 2.0 were scored as negative results. The genotoxic potency for samples scored as positive result was further expressed as water volume (WV) required giving a positive result (IR 2.0) obtained from the dose-response relationship.

$\mathrm{WV}=\frac{V V_{1} V_{\mathrm{w}}}{5 \mathrm{n} V_{2} V_{\mathrm{t}}}$

where $V_{\mathrm{W}}$ is the water volume for extract $(\mathrm{L}), \mathrm{n}$ is the dilution rate at $\mathrm{IR}=2.0, V_{\mathrm{t}}$ is the bulk solution volume redissolved in $200 \mu \mathrm{L}$ DMSO, $V$ is the volume of bulk solution for the concentration sequences $(50 \mu \mathrm{L}), V_{1}$ is the volume of culture in SOS/umu test $(\mu \mathrm{L}), V_{2}$ is the volume of the bulk solution on different concentration sequences. For WV was obtained from the dose-response curve in a similar manner as other toxicological endpoints, it can reflect the relative genotoxic potency of water samples from different source and does n't depend on the water amount used for extraction and characteristics of water contaminants. Compared with IR, the WV can be more scientifically justified endpoint (Xiao et al. 2006).

The bioassay procedure has been validated in our laboratory for measuring the dioxin-like activity in environmental samples (Ma et al. 2005). H4IIE rat hepatoma cells were grown in Dulbecco's minimum essential medium supplemented with $10 \%$ fetal calf serum at $37^{\circ} \mathrm{C}$, in a humidified $5 \% \mathrm{CO}_{2}$ incubator. The cell culture and EROD bioassay were performed following Donato's method (Donato et al. 1992). For each concentration level, three duplicates and 2,3,7,8-tetrachlorodibenzo- $p$-dioxin (TCDD) standard (Cambridge Isotope Laboratories, Inc.) and DMSO solvent control were used on one 96-well plate. Thereafter the total protein content was measured as described by Bradford (1976). Data obtained from EROD assays were normalized to total cellular protein. The biological TCDD equivalence (TCDD-EQ) values were calculated according to Ma et al. (2005) by comparing the induction of enzyme activity by environmental sample extracts with that of the TCDD standard curve. The doseresponse curves for the induction of EROD activity were constructed by ALLFIT computer software (DeLean et al. 1992).

In all the bioassays, replication and subsequent performance checks were performed at many stages of the bioassay procedure. The composite TCDD, 4-NQO and
$\mathrm{BaP}$ dose-response curve was generated from the average of six independent determinations for each composite sample. Triplicate assays were conducted on $10 \%$ of water samples, as were all positive control and some matrix blank samples. Positive control extracts were analyzed on each assay date along with the samples. The procedural blank, which had been subjected to solid phase extraction, was also analyzed in parallel to the samples to monitor for false positive results.

\section{Results and Discussion}

Organic extracts from water samples manifested no cytotoxicity to Salmonella typhimurium TA1535/pSK1002. S9 metabolic activation did not affect the growth of the test bacterium. The GRs were between $98 \%$ and $113 \%$ (Fig. 2), excepting one from the anoxic unit effluent (B), which showed $136 \%$ induction of biomass after S9 metabolic activation. The growth of Salmonella cultures was not decreased by any sample extracts indicating the absence of cytotoxicity. Dizer et al. (2002) also reported a lack of cytotoxicity in the waste water extracts. Increase the biomass of bacteria was also found in some water samples. For example, Dizer et al. (2002) reported that the presence of a variety of chemicals in surface waters which induced activity or associated with toxic agents might induce biomass of test bacteria.

Genotoxicity measured by the SOS/umu test was presented by both the IR values and WVs (listed in Table 1).

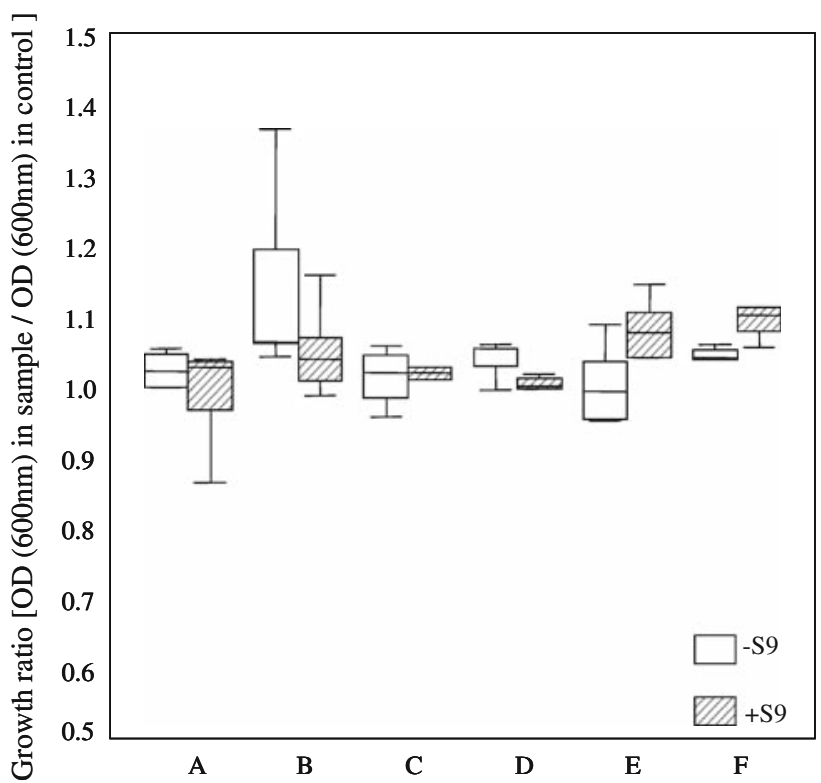

Fig. 2 Growth ratio as a measure of cytotoxicity in surface water samples from waste water treatment plant and receiving river with or without S9 enzyme fraction. Growth ratio $<0.8$ : significant cytotoxicity; OD: optical density; S9: microsomal fraction 
Table 1 Induction ratio (IR) as a measure of genotoxicity in extract of water samples from waste water treatment plant and receiving river by umu-assay with or without adding $S 9$ enzyme fraction (IR $>2.0$ : significant genotoxicity $(+)$, IR $<2.0$ : not significant genotoxicity $(-)$; WV is defined as the water volume required for positive result (IR 2.0)

\begin{tabular}{|c|c|c|c|c|c|c|}
\hline \multirow[t]{2}{*}{ Sampling site } & \multicolumn{3}{|l|}{$-\mathrm{S} 9$} & \multicolumn{3}{|l|}{$+\mathrm{S} 9$} \\
\hline & IR & & $\mathrm{WV}\left(\mathrm{mL}\right.$ cell $\left.^{-1}\right)$ & IR & & $\mathrm{WV}\left(\mathrm{mL}\right.$ cell $\left.^{-1}\right)$ \\
\hline A & $1.5 \pm 0.1$ & - & nd & $21.2 \pm 0.2$ & + & 1 \\
\hline B & $1.1 \pm 0.1$ & - & nd & $25.3 \pm 1.1$ & + & 1 \\
\hline $\mathrm{C}$ & $3.5 \pm 0.1$ & + & 20 & $23.4 \pm 0.8$ & + & 1 \\
\hline $\mathrm{D}$ & $3.6 \pm 0.1$ & + & 18 & $2.3 \pm 0.1$ & + & 15 \\
\hline E & $3.1 \pm 0.1$ & + & 23 & $2.7 \pm 0.1$ & + & 18 \\
\hline $\mathrm{F}$ & $1.2 \pm 0.1$ & - & nd & $2.7 \pm 0.2$ & + & 9 \\
\hline Con. & $1.0 \pm 0.1$ & & & $1.0 \pm 0.1$ & & \\
\hline
\end{tabular}

At a given water volume for extraction and in the absence of metabolic activation, the IR values varied from 0.6 to 3.6. IR values for the effluent sample (C) and for those from 2 and $4 \mathrm{~km}$ (D and $\mathrm{E}$ ) along the river were $<2.0$. The calculated WVs were 20,18 , and $23 \mathrm{~mL}^{-1}$ cell $^{-1}$ for these samples (C, D, and E, respectively). Metabolic activation greatly enhanced the genotoxic effects of all samples and produced IR values as high as 25.3. The produced water samples' WVs were almost $1 \mathrm{~mL}$ cell $^{-1}$ indicating strong genotoxic potential. In river water samples, the WVs were 15,18 , and $9 \mathrm{~mL} \mathrm{cell}^{-1}$, respectively, also demonstrating significant reduction in genotoxic potential after the effluent was discharged into the river. WVs obtained with metabolic activation was lower than the values without metabolic activation. This result indicated that oilfield produced water contained a large number of potentially indirect genotoxic compounds. It has been reported that oilfield produced water contains numerous aliphatic and aromatic hydrocarbons, PAHs, phenols, and other chemical products (Camposa et al. 2002). Some high molecular weight PAHs, such as benzo(a)pyrene, dibenzo(a, h)anthracene, benzo(b)fluoranthene, and benzo(k)fluroranthene are renown for their mutagenic and/or clastogenic activity. The levels of PAHs in oilfield produced water from Oseberg, Norway, from 1998 to 2000 ranged from 1.9 to $2.4 \mu \mathrm{g} \mathrm{L}^{-1}$ (OGP 2002). In addition, the genotoxicity of PAHs needs metabolic activation. Several studies have confirmed that genotoxic water contains a variety of genotoxic PAHs and PAH derivatives that are not usually detected by routine chemical analyses (Kira et al. 1999).

The results also suggest that the biological treatment system was not efficient for removal of the genotoxic compounds. Previous studies reported that conventional wastewater processes did not effectively remove many chemical contaminants, and may actually increase the genotoxicity of wastewaters (Claxton et al. 1998). In fact, Shuttleworth et al. (1995) reported that the high molecular weight PAHs, many of which are strong genotoxins, seem to be recalcitrant to microbial degradation. After discharge into the receiving water, genotoxicity decreased rapidly along the effluent dispersion plume was probably due to the rapid dilution by the receiving water. In addition, OGP (2002) reported that after discharge, the high molecular weight PAHs many of which had genotoxicity would tend to associate with particulates and oil droplets in produced water. While the present investigation demonstrated genotoxic effects in the oilfield wastewater and the receiving river, the precise source and identity of the causative agents remain uncertain.

AhR-agonistic effects were detected in all samples (Fig. 3) indicating the presence of AhR-agonistic compounds; that is, compounds capable of binding AhR and inducing EROD activity. TCDD-EQs in these water samples ranged from $16.7 \mathrm{pg} \mathrm{L}^{-1}$ in the waste water treatment plant (WWTP) to $1.8 \mathrm{pg} \mathrm{L}^{-1}$ following water treatment and dilution in the river. The higher AhR-agonistic effects were observed in the WWTP waters (Fig. 3; TCDDEQs $>13$ pg L $^{-1}$ ). Deschamps and Allard (2004) reported comparable AhR-agonistic values in wastewater effluents of a petrochemical complex. Ma et al. (2005) similarly reported TCDD-EQs of $14 \mathrm{pg} \mathrm{L}^{-1}$ in a wastewater

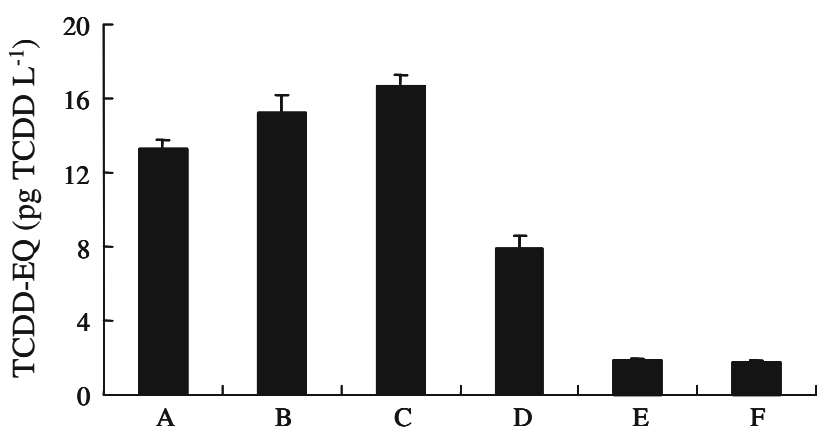

Fig. 3 Bioassay-derived dioxin equivalents in produced water (a), water samples in a waste water treatment plant (b and c) and a river receiving treated effluents (d)-(f). TCDD-EQ: 2,3,7,8-tetrachlorodibenzo- $p$-dioxin equivalence 
treatment plant in Beijing city. However, even the highest value, i.e., $16.7 \mathrm{pg} \mathrm{L}^{-1}$ TCDD-EQ at $\mathrm{C}$, was below the drinking water maximum contaminant level of $30 \mathrm{pg} \mathrm{L}^{-1}$ recommended by USEPA (2002). Once the effluents were diluted in the river, however, TCDD-EQs were estimated to be less than $2 \mathrm{pg} \mathrm{L}^{-1}$. Therefore, the AhR-agonistic potential of wastewater discharge should not be identified as a major concern. The TCDD-EQs for samples B and C demonstrate that aerobic/anaerobic biological treatments did not reduce the toxic potential of the produce water and, in contrast, tended to increase it. Therefore, the dilution of effluents in the receiving water is principally responsible of the reduction of TCDD-EQs. It is well known that AhRagonistic chemicals including polychlorinated dibenzo- $p$ dioxins and dibenzofurans (PCDD/Fs), PCBs, polychlorinated naphthalenes (PCNs), and PAHs are responsible for the AhR-agonistic effects (Safe 1990). Most of the AhRagonistic chemicals are highly resistant to anoxic and aerobic degradation. Once diluted in the river, the TCDDEQs (Fig. 3) were similar to those derived from chemical analysis in the Baltic Sea ranged from 0.4 to $3.6 \mathrm{pg} \mathrm{L}-1$ (Witt 1995). While the TCDD-EQs in the surface water are estimated to be relatively low, the total charge of AhRagonistic chemicals to the river may be significant and may be associated with accumulation in river sediments and biota.

In conclusion, by using a battery of bioassays, levels of genotoxic and AhR-agonistic chemicals in effluent of WWTP and receiving river could be evaluated. The results of bioassays demonstrated that the biological treatment did not effectively reduce the level of genotoxic and AhRagonistic chemicals. Assessment of the river water sampled downstream of WWTP revealed the presence of indirect genotoxic chemicals, which will affect people living downstream and using river water for drinking. However, AhR-agonist levels in the river water were lower than the maximum contaminant level recommended by USEPA.

Acknowledgment This study was supported by the National Natural Science Foundation of China (20621703, 50538090).

\section{References}

Bradford MM (1976) A rapid and sensitive method for the quantitation of microgram quantities of protein utilizing the principle of protein-dye binding. Anal Biochem 72:248-254. doi:10.1016/0003-2697(76)90527-3

Camposa JC, Borges RMH, Oliveira AM (2002) Oilfield wastewater treatment by combined microfiltration and biological processes. Water Res 36(1):95-104. doi:10.1016/S0043-1354(01)00203-2

Claxton LD, Houk VS, Hughes TJ (1998) Genotoxicity of industrial waste and effluents. Mutat Res 410:237-243
DeLean A, Munson PJ, Guardabasso V, Rodbard D (1992) A user's guide to ALLFIT. Simultaneous fitting of families of sigmoidal dose response curves using the four-parameter logistic equation. Lab theoret physical biology, Natl Inst Child Health and Human Development, NIH, Bethesda, MD

Deschamps M, Allard JL (2004) Assessment of PCDDs-PCDFs emissions from the Copesul/south petrochemical complex located in southern Brazil. Organohalogen compounds 66:1615-1620

Dizer H, Wittekindt E, Fischer B (2002) The cytotoxic and genotoxic potential of surface water and wastewater effluents as determined by bioluminescence, umu-assays and selected biomarkers. Chemosphere 46:225-233. doi:10.1016/S0045-6535(01)00062-5

Donato MT, Castell JV, Gómez-Lechón J (1992) A rapid and sensitive method for measuring monooxygenase activities in hepatocytes cultured in 96-well plates. J Tissue Cult Meth 14:153-158. doi:10.1007/BF01409106

Dórea HS, Bispoa JRL, Aragãoa KAS, Cunhaa BB, Navickienea S, Alvesa JPH (2007) Analysis of BTEX, PAHs and metals in the oilfield produced water in the State of Sergipe, Brazil. Microchemical J 85(2):234-238. doi:10.1016/j.microc.2006.06.002

Giesy JP, Hilscherova K, Jones PD, Kannan K, Machala M (2002) Cell bioassays for detection of aryl hydrocarbon (AhR) and estrogen receptor (ER) mediated activity in environmental samples. Marine Pollut Bull 45:3-16. doi:10.1016/S0025326X(02)00097-8

ISO/DIS 13829, DIN 38415 T3. 2000. Genotoxicity assay: umu-test

Kira S, Nogami Y, Ito T, Hayatsu H (1999) Detection of benzo(a)pyrene and mutagenicity in water of lake Baikal (Russia) and rivers in Okayama (Japan) using the blue rayon method: a simplified handling and transportation of samples from remote sites. Environ Toxicol 14:279-284. doi:10.1002/ (SICI)1522-7278(199905)14:2<279::AID-TOX9>3.0.CO;2-P

Ma M, Li J, Wang Z, (2005) Assessing the detoxication efficiencies of wastewater treatment processes using a battery of bioassays/ biomarkers. Arch Environ Contam Toxicol 49:480-487. doi:10.1007/s00244-004-0204-Z

OGP (2002) Aromatics in produced water: occurrence, fate and effects, and treatment, international association of oil and gas lproducers, report No.1.20/324

Oda Y, Nakamura S, Oki I, Kato T, Shinagawa H (1985) Evaluation of the new system (umu test) for the detection of environmental mutagens and carcinogens. Mutat Res 147:219-229

Qiao M, Chen YY, Zhang QH (2006) Identification of Ah receptor agonists in sediment of Meiliang bay, Taihu lake, China. Environ Sci Technol 40:1415-1419. doi:10.1021/es051456p

Safe S (1990) Polychlorinated biphenyls (PCBs), dibenzo-p-dioxins (PCDDs), dibenzofurans (PCDFs), and related compounds: environmental and mechanistic considerations which support the development of toxic equivalency factors (TEFs). Crit Rev Toxicol 21:51-88. doi:10.3109/10408449009089873

Shuttleworth KL, Cerniglia CE (1995) Environmental aspects of PAH biodegradation. Appl Biochem Biotechnol 54:291-302. doi:10.1007/BF02787927

USEPA (2002) 2002 Edition of the Drinking water standards and Health advisories, EPA 822-R-02-038, Office of Water, US Environmental Protection Agency Washington, DC

Witt G (1995) Distribution of petroleum hydrocarbons in Baltic Sea water 1992-1994. Dt Hydrogr Z 47(3):231-245. doi:10.1007/ BF02736205

Xiao RY, Wang ZJ, Wang CX, Yu G (2006) Soil screening for identifying ecological risk stressors using a battery of in vitro cell bioassays. Chemosphere 64:71-78. doi:10.1016/ j.chemosphere.2005.11.048 